\title{
Reduction of oil uptake in deep fat fried falafel
}

\section{Introduction}

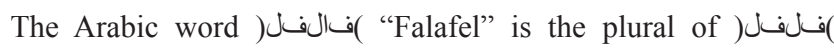
"pepper". Falafel is a fried ball principally made of spiced fava beans and/or chickpeas. It is a popular form of fast food in the Middle East Brothwell \& Brothwell. ${ }^{1}$ Falafel was invented some 1000years ago by the Egyptian Copts, who brought it with them to the rest of the Middle East originally made with fava beans. The dish migrated northwards to Syria and Palestine where chickpeas were introduced instead. The chickpea was used as a food item in the levant before $4000 \mathrm{BC}$ Jodi K. ${ }^{2}$ Fat and calorie content of falafel are of concern to healthy consumers, Lefort et al., ${ }^{3}$ Fats (lipids) are implicated in cardiovascular disease due to the fact that the product constitutes a major source of energy content $(9 \mathrm{Kcal} / \mathrm{g})$; eating high fat diet is conducive to obesity Baur. ${ }^{4}$ Therefore, high oil content is a major factor affecting consumer acceptance of oil-fried products today, as well as low fat food products are becoming more popular, Bunger et al., ${ }^{5}$ Saturated fat and trans-fat are the undesirable fats Allan. ${ }^{6}$

In many countries medical authorities have implicated a high fat diet as being one of the most conducive factors to cardiovascular disease Glew. ${ }^{7}$

During the last 10years, the American Heart Association and other health organizations have encouraged limitation of fats in foods to less than $30 \%$ of calories for most people. ${ }^{8,9}$

Reducing the oil content in falafel is also motivated by other several reasons; oil is a costly raw material and is an important determinant of the cost of product, as well as neither study was applied to determine the oil content of any kind of falafel, nor reducing their oil content. High oil content makes falafel balls greasy or oily. On the other hand it would be health-wise rewarding if it becomes possible to make falafel balls less greasy then healthier. However, there have been many techniques applied to reduce the fat content of frying products.

\section{Review of literature}

Numerous coating materials could be used. Gold ${ }^{10}$ disclosed the treatment with an aqueous hydrocolloid solution, which is methylcellulose, hydroxypropylcellulose, carboxymethylethyl cellulose (CMC).

Albert et al. experimented 11 hydrocolloid materials including gelatin, gellan gum, k-carrageenan- konjac-blend, locust bean gum, methyl cellulose (MC), microcrystalline cellulose, pectin (three types), sodium caseinate, soy protein isolate (SPI), vital wheat gluten, and whey protein isolate (WPI). These materials were compared for their film forming ability and suitability for fried foods, water and fat transfer properties.

Gelatin, wheat gluten, and sodium caseinate were not suitable in single material coating. The SPI, WPI, and MC were the best materials for coating to reduce fat uptake during frying. SPI/MC and SPI/WPI mixed coatings provided the highest index value (reduction in fat uptake/decrease of water loss), and reduced the fat uptake up to $99.8 \%$, Albert et al., ${ }^{11}$
Volume 2 Issue 4 - 2015

Tony Abdullah

Department of Nutrition and Food Science, University of Kalamoon, Syria

Correspondence: Tony Abdullah, Department of Nutrition and Food Science, University of Kalamoon, Deir Atiah, Syria, Tel 00963944629298,Email abdallatony@hotmail.com

Received: March 5, 2015 | Published: September 10, 2015

Results obtained indicate that the ability to reduce oil uptake in this product decreases in the following order: gum Arabic $>$ carrageenan $>$ gum karaya $>$ guar gum $>$ carboxymethyl cellulose $>$ hydroxypropylmethyl cellulose.

Hydrocolloids such as xanthan, gum ghatti, gum tragacanth, and locust bean gum were found to be ineffective $(<10 \%$ reduction in oil content), Annapure et al., ${ }^{12}$

Ferrero et al., ${ }^{13}$ used methylcellulose (MC) and hydroxypropylmethylcellulose (HPMC) in coating formulations to reduce the oil uptake in deep-fat frying potato strips. MC coatings were more effective in reducing oil uptake than HPMC ones. The effect of plasticizer addition (sorbitol) was also evaluated. The best formulations were $1 \% \mathrm{MC}$ and $0.5 \%$ sorbitol for fried potatoes. For these formulations, oil uptake reduction was $40.6 \%$ for potato strips compared to the uncoated samples. Non-significant differences in texture of coated and uncoated samples were observed.

\section{Materials and methods}

\section{Materials}

i. The readymade mix for frying falafel was obtained from domestic market. The mix was produced every time from the same vender.

ii. Edible sunflower oil was obtained from local markets.

iii. CMC, Gum Arabic, as well as partially methoxylated pectin were used.

\section{Methods}

a) Falafel balls were made by a manual utensil. Each ball has a diameter of about $1.5 \mathrm{~cm}$ and $0.5 \mathrm{~cm}$ of thickness. Six balls of falafel were prepared at one time for a direct frying operation. Falafel balls were fired by a small 5liters electrical fryer.

b) The temperature of frying was kept at $180^{\circ} \mathrm{C}$ for duration of five minutes. At the time of starting a frying operation the oil quantity was kept at the level of 2liters. 
c) Every treatment was repeated three times and the average was calculated on the basis of three replicates. Oil content was determined by Soxhlet apparatus. Hexane was used as a solvent in the oil extraction operation. Soxhlet method could be summarized by which the solvent builds up in the extraction chamber for 5-10minutes and completely surrounds the samples, and then siphons back to the boiling flask. Fat content is measured by weight loss of the samples or by weight of fat removed.

d) Two different treatments were effected; immersion, and spraying.

\section{Immersion treatments were as follows}

i. Addition of $1.5 \mathrm{Tbs}=10-11.5 \mathrm{~g}$ (according to texture) of a solution of $1 \% \mathrm{CMC}$ to the quantity to be fried of falafel.

ii. Addition of $1.5 \mathrm{Tbs}=10-11.5 \mathrm{~g}$ (according to texture) of a solution of $1 \%$ Pectin to the quantity to be fried of falafel.

iii. Addition of $1.5 \mathrm{Tbs}=10-11.5 \mathrm{~g}$ (according to texture) of a solution of $1 \%$ Gum Arabic to the quantity to be fried of falafel (Figure 1).

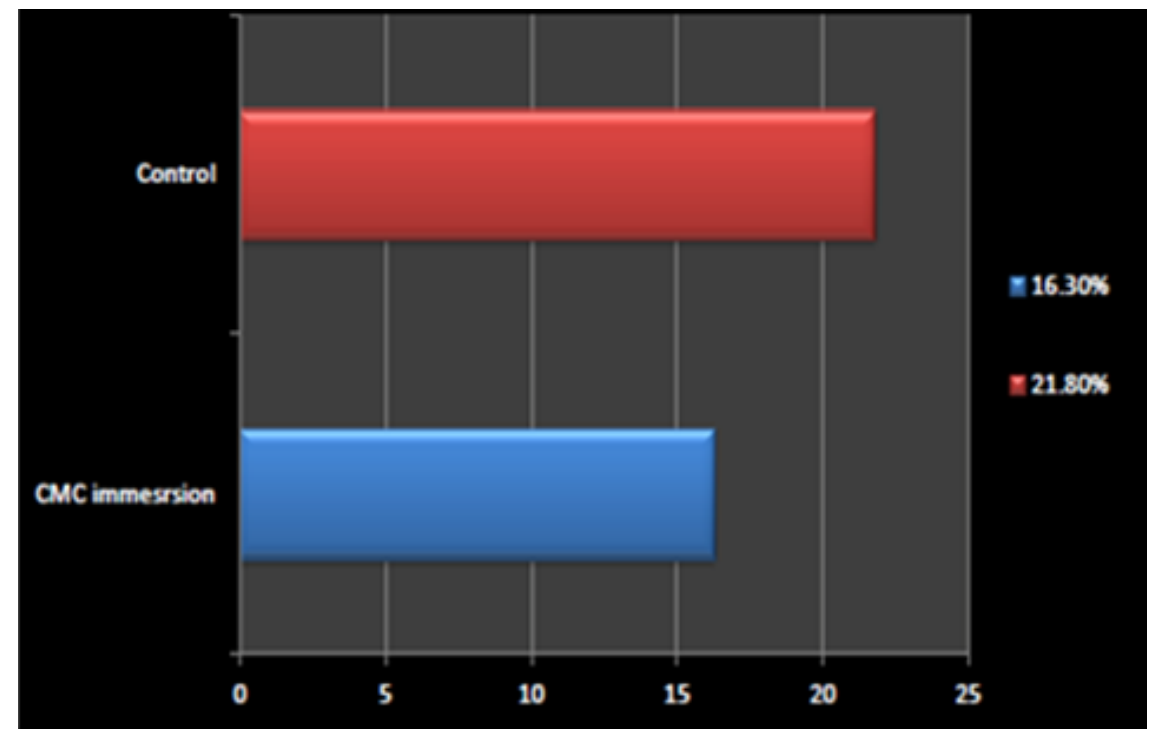

Figure I \% oil content in one immersion treatment.

\section{Spraying treatments were as follows}

a) Spraying of a solution of $1 \% \mathrm{CMC}$ to each falafel ball to be fried.

b) Spraying of a solution of $1 \%$ Pectin to each falafel ball to be fried.

c) Spraying of a solution of $1 \%$ Gum Arabic to each falafel ball to be fried (Figure 2).

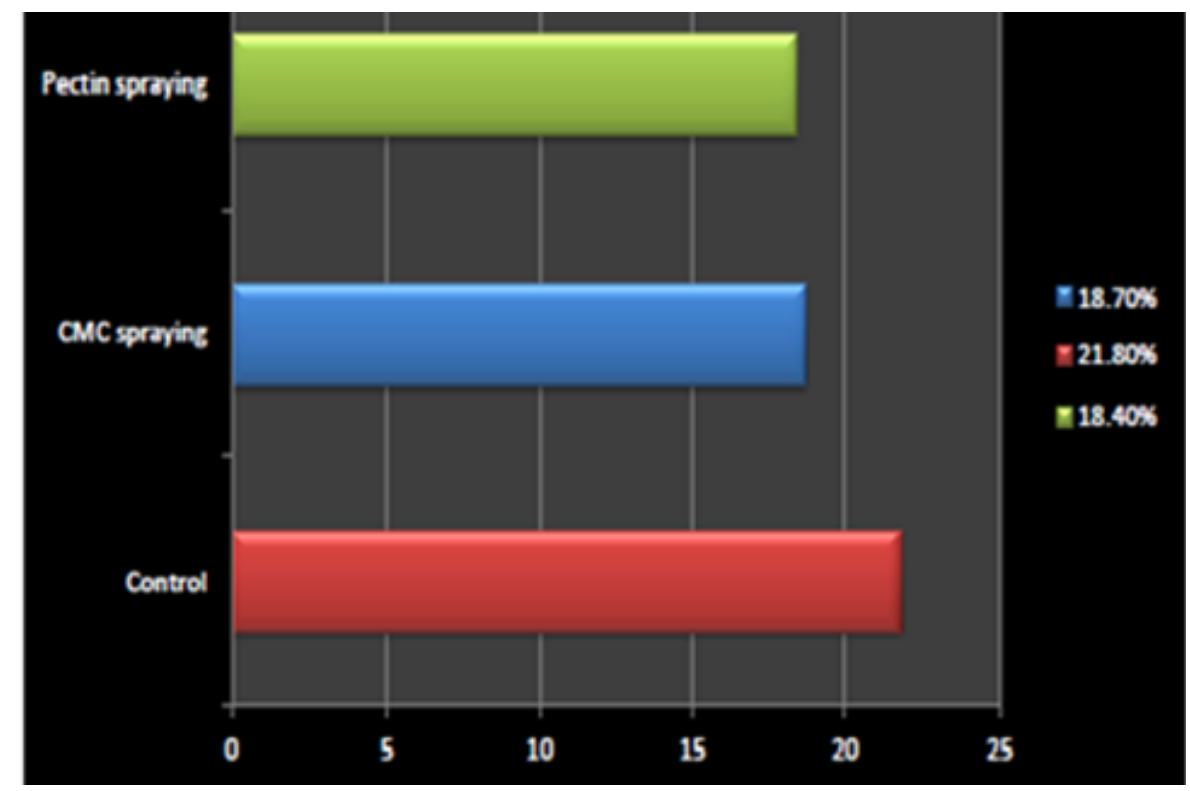

Figure $2 \%$ oil content in two spraying treatments. 


\section{Results and discussion}

i. $\mathrm{CMC}$ immersion was the most effective method among the other methods used in all treatments.

ii. Pectin spraying was more effective than CMC spraying.

iii. No differences were noticed as per all treatments in texture, color, ripening, and taste.

iv. Gum Arabic methods couldn't be analyzed due to technical problems and foaming related to its nature.

v. Pectin immersion treatment couldn't be analyzed due to technical problems similar to that related to Gum Arabic.

The results presented in Table 1 show that $\mathrm{CMC}$ immersion resulted in reduction of oil uptake in fried falafel balls of $25.2 \%$ compared by $14.2 \%$ attained by the spraying treatment.

Spraying with a pectic dispersion, while it would be impractical to adopt at present time, showed results that were very close to CMC spraying treatment (Figure 3).

The mechanism of action of hydrocolloid derivatives is attributed to formation of an oil resistant barrier film, an alteration in surface hydrophobicity of the product being fried, and the thermal gelation.

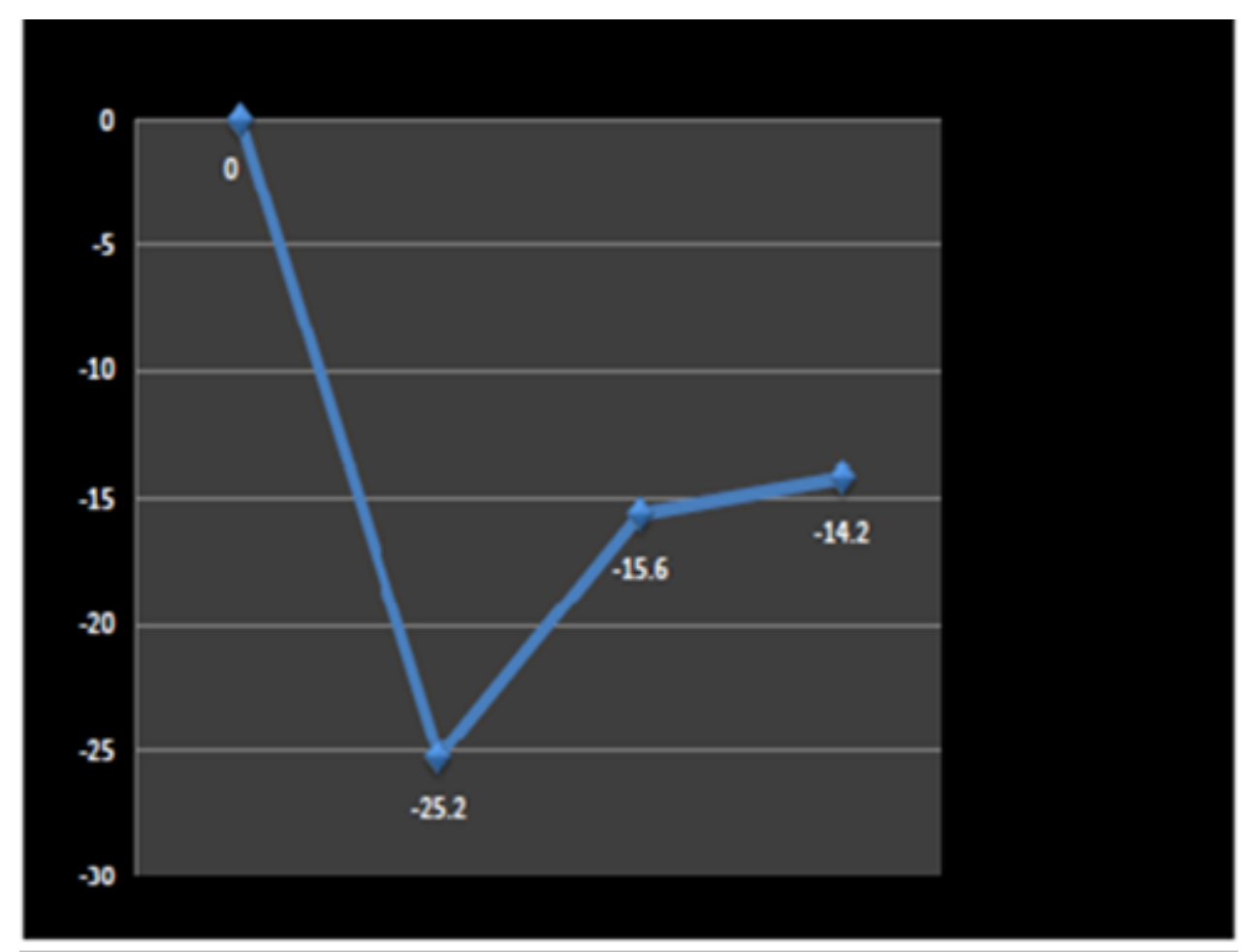

Figure $3 \%$ oil uptake reduction in three treatments.

0\%, Control; - $25.2 \%$, CMC immersion; - 15.6\%, Pectin spraying; - 14.2\%, CMC spraying

Table I CMC immersion resulted in reduction of oil uptake in fried falafel balls of $25.2 \%$ compared by $14.2 \%$ attained by the spraying treatment

\begin{tabular}{llllllll}
\hline & Control & $\begin{array}{l}\text { CMC } \\
\text { immersion }\end{array}$ & $\begin{array}{l}\text { CMC } \\
\text { spraying }\end{array}$ & $\begin{array}{l}\text { Pectin } \\
\text { immersion }\end{array}$ & $\begin{array}{l}\text { Pectin } \\
\text { spraying }\end{array}$ & $\begin{array}{l}\text { Gum arabic } \\
\text { immersion }\end{array}$ & $\begin{array}{l}\text { Gum arabic } \\
\text { spraying }\end{array}$ \\
\hline $\begin{array}{l}\text { Average Oil } \\
\text { Content }\end{array}$ & $21.80 \%$ & $16.30 \%$ & $18.70 \%$ & $*$ & $18.40 \%$ & $*$ & $*$ \\
$\begin{array}{l}\text { Average Oil } \\
\text { Decrease }\end{array}$ & - & $-25.20 \%$ & $-14.20 \%$ & $*$ & $-15.60 \%$ & $*$ & $*$ \\
\hline
\end{tabular}

*, Couldn't be analyzed due to technical problems and foaming related to its nature.

\section{Acknowledgments}

To all who participated and gave a hand to make this project possible...... Tony D. Abdullah February 2009.

\section{Conflict of interest}

Author declares that there is no conflict of interest.

\section{References}

1. Brothwell \& Brothwell. 1990:105-107.

2. Jodi K. A History of the Mideast in the Humble Chickpea. The New York Times; 2002.

3. Lefort JF, Durance TD, Upadhyaya MK. Effects of tuber storage and cultivar on the quality of vacuum microwave-dried potato chips. Journal of Food Science. 2003;68(2):690-696. 
4. Baur FJ. Nutritional Aspects of Oils and Fats (Chapter 13). In: Chapman \& Hall, editor. Food oils and fats: technology, utilization, and nutrition. New York, USA; 1995. p. 203-280.

5. Bungers A, Moyano P, Rioseco V. NaCl soaking treatment for improving the quality of french- fried potatoes. Food Research International. 2003;36(2):161-166

6. Allan B. More fat with that. Consumer. 2004;433:10-11.

7. Glew G. Large-scale catering. In: Varela G, editor. Frying of food principles, changes, new approaches. Chichester, England: Ellis Horwood; 1988. p. 191-198.

8. Food and Nutrition Service (USDA). Building for the future: nutrition guidance for the child nutrition programs. Educational Resources Information Center (ERIC). 1990.
9. USDA \& USDHHS. Dietary Guidelines for Americans. 3rd ed. USA, Washington, DC. 1990.

10. http://www.google.co.in/patents/US3424591

11. Albert. School of engineering. University of Guelph, Guelph, Canada N1g 2W1; 2001.

12. Annapure. University Department of Chemical Technology. Food and Fermentation Technology Division. Nathal Parikh Marg, Matunga, India. 1999.

13. Ferrero. Centro de investigation y Desarrollo en criotecnologia de alimentos (CIDCA). CONICET, Universidad Nacional de la plata, $47 \mathrm{y}$ 116, la Plata, Argentina, 3 October 2002. 1900. 